\title{
The prevalence of various eyelid skin lesions in a single-centre observation study
}

\author{
Wojciech Z. Adamski ${ }^{1}$, Jakub Maciejewski², Kinga Adamska³, Andrzej Marszałek ${ }^{4}$, Iwona Rospond-Kubiak ${ }^{1}$
}

${ }^{1}$ Ocular Oncology Service, Department of Ophthalmology, Poznan University of Medical Sciences, Poznan, Poland 'Students' Scientific Society, Poznan University of Medical Sciences, Poznan, Poland ${ }^{3}$ Department of Dermatology and Venerology, Poznan University of Medical Sciences, Poznan, Poland ${ }^{4}$ Department of Tumour Pathology and Prophylaxis, Poznan University of Medical Sciences, Greater Poland Cancer Centre, Poznan, Poland

Adv Dermatol Allergol 2021; XXXVIII (5): 804-807 DOI: https://doi.org/10.5114/ada.2020.95652

\begin{abstract}
Introduction: The role of the eyelids is to protect and moisturise the eye. Despite its small relative surface area, $5-10 \%$ of skin cancers originate in the eyelids.

Aim: To assess the prevalence of different types of skin lesions in the area of eyelids based on retrospective histopathology data from a tertiary centre.

Material and methods: Among 544 included eyelid lesions, 429 (79\%) were benign and 115 (21\%) were malignant. In the benign group, the most common finding was a chalazion (49.2\%) followed by squamous papilloma (22.8\%), seborrheic keratitis (10\%), epidermal cyst (8.2\%), and intradermal nevus (5.1\%). Out of all malignant lesions, the most common diagnosis was basal cell carcinoma (BCC) in $110(95.7 \%)$ patients.

Results: Squamous cell carcinoma (SCC) was diagnosed in $3(2.6 \%)$ patients and sebaceous gland carcinoma (SGC) in $2(1.7 \%)$. No malignant melanoma was identified in the studied group.

Conclusions: Although benign lesions are the most common eyelid tumours, it is essential to differentiate between benign and malignant eyelid tumours because early detection and appropriate treatment may improve the cosmetic effect and reduce recurrences.
\end{abstract}

Key words: eyelid lesion, skin cancer, basal cell carcinoma.

\section{Introduction}

The primary role of the eyelid is to protect and moisturise the eye. Any sort of neoplasm affecting the eyelid may cause its malposition and in consequence be vision-threatening for the patient.

Anatomically, the eyelid has four layers: skin with thin subcutaneous tissue, striated muscle (orbicularis oculi), tarsal plate and conjunctiva. The skin covering the eyelids is thin, unlike in other regions of the body, and does not contain a layer of subcutaneous fat. It has, however, typical histologic composition of the normal skin: keratinised epithelium, melanocytes, blood and lymphatic vessels, nerve fibres and several types of glands: sweat glands, apocrine glands (glands of Moll) and sebaceous glands (glands of Zeiss). A second layer of the eyelid contains the orbicularis muscle ('purse' muscle) that covers the whole entrance to the orbit and is responsible for closing the eyelids and for the lacrimal pump. A third layer is a tarsus or tarsal plate composed of thick connective tissue. The tarsi give the eyelid its shape and firmness. What is more, they contain a number of sebaceous glands called the Meibomian glands that are responsible for the stability of the tear film on the surface of the eye. The fourth layer of the eyelid is the palpebral conjunctiva that contains typical conjunctival epithelium and stroma, numerous glands including goblet cells that secrete mucus, which is another ingredient of the tear film [1].

Despite the relatively small surface area comparing to the skin in other regions, approximately $5-10 \%$ of all skin cancers originate from the eyelids, primarily [2] because of their exposure to sunlight and environmental factors.

Address for correspondence: Dr Wojciech Z. Adamski, Ocular Oncology Service, Department of Ophthalmology, Poznan University of Medical Sciences, Poznan, Poland, phone: +48 604149 157, e-mail: wojciech.adamski@ump.edu.pl Received: 19.04.2020, accepted: 9.05.2020. 
The aim of this study was to assess the prevalence of different types of benign and malignant skin lesions in the area of eyelids basing on the tertiary centre experience.

\section{Material and methods}

Data of patients treated at the Department of Ophthalmology, Poznan University of Medical Sciences between January 2013 and January 2017 were retrospectively reviewed. Patients were included in the study if they underwent the surgical treatment for the eyelid lesions with a histopathological report. They were excluded if the patient underwent previous surgery for palpebral mass or if the lesion penetrated into the orbit or affected the bones.

The histopathology techniques included standard $\mathrm{H}+\mathrm{E}$ sections and when needed immunohistochemical studies, too. Collected data included age, gender, location and the type of the tumour.

\section{Results}

Five hundred, fourty-four patients were identified, 201 men and 343 women in the mean age of 60.5 years (range: 18-92). All the lesions were surgically removed with standard reconstruction techniques. There was a slight predominance in the affected side, with majority of the lesions (57\%) located in the left eyelids.

Among all 544 eyelid lesions included in the study, 429 (79\%) tumours were benign and 115 (21\%) - malignant. In the benign group, the most common finding was chalazion (49.2\%) followed by squamous papilloma (22.8\%), seborrheic keratitis (10\%), epidermal cyst (8.2\%), and intradermal nevus (5.1\%). The detailed diagnoses of benign lesions are listed in Table 1, and some typical examples shown on Figures 1-3.

Out of all malignant lesions, the most common diagnosis was basal cell carcinoma (BCC) in 110 (95.5\%) patients. Squamous cell carcinoma (SCC) was diagnosed in 3 (2.6\%) patients and sebaceous gland carcinoma (SGC) in 2 (1.7\%). Table 2 contains the detailed diagnoses of malignant lesions. Figures 4 and 5 show basal cell carcinoma and Figure 6 shows a squamous cell carcinoma with a cutaneous horn.

In the BCC group, the most frequent location of the tumour was the lower eyelid - in 78\%. The upper eyelid was affected in $15 \%$ and the medial canthal area in $8 \%$. According to histopathology, 46 BCC lesions (41.8\%) were nodular, 12 (10.9\%) were ulcerative and 10 (9.1\%) superficial. In 42 cases (38.2\%), the histopathology report did not include the type of BCC. All histopathology diagnoses are listed in Table 3.

\section{Discussion}

This is a study reporting the incidence of various eyelid skin lesions basing on the single-centre experience. The majority of analysed lesions were benign (79\%).
Table 1. Prevalence of benign lesions in the studied group

\begin{tabular}{lcc}
\hline Lesion & $\boldsymbol{N}$ & $\%$ \\
\hline Chalazion & 211 & 49.2 \\
\hline Squamous papilloma & 98 & 22.8 \\
\hline Seborrheic keratitis & 43 & 10.0 \\
\hline Epidermal cyst & 35 & 8.2 \\
\hline Intradermal nevus & 22 & 5.1 \\
\hline Pyogenic granuloma & 8 & 1.9 \\
\hline Hidrocystoma & 7 & 1.6 \\
\hline Molluscum contagiosum & 5 & 1.2 \\
\hline
\end{tabular}

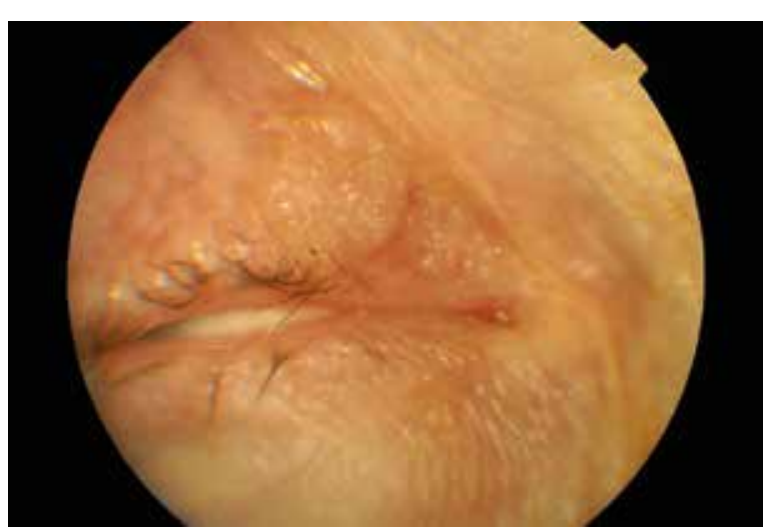

Figure 1. Seborrheic keratitis

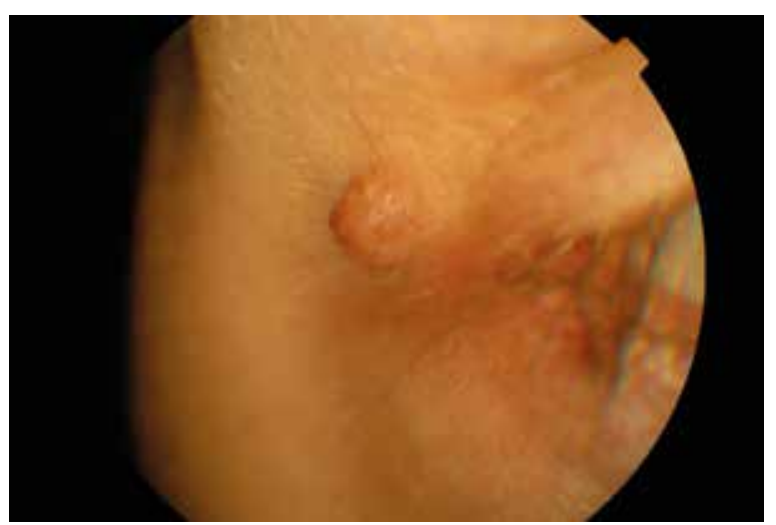

Figure 2. Intradermal nevus

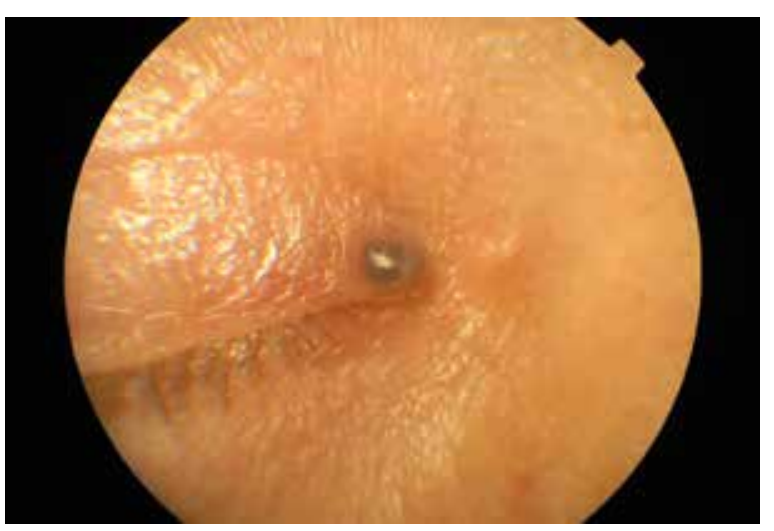

Figure 3. Epidermal cyst 
Table 2. Prevalence of malignant lesions in the studied group

\begin{tabular}{lcc}
\hline Lesion & N & $\%$ \\
\hline Basal cell carcinoma & 110 & 95.7 \\
\hline Squamous cell carcinoma & 3 & 2.6 \\
\hline Sebaceous gland carcinoma & 2 & 1.7 \\
\hline
\end{tabular}

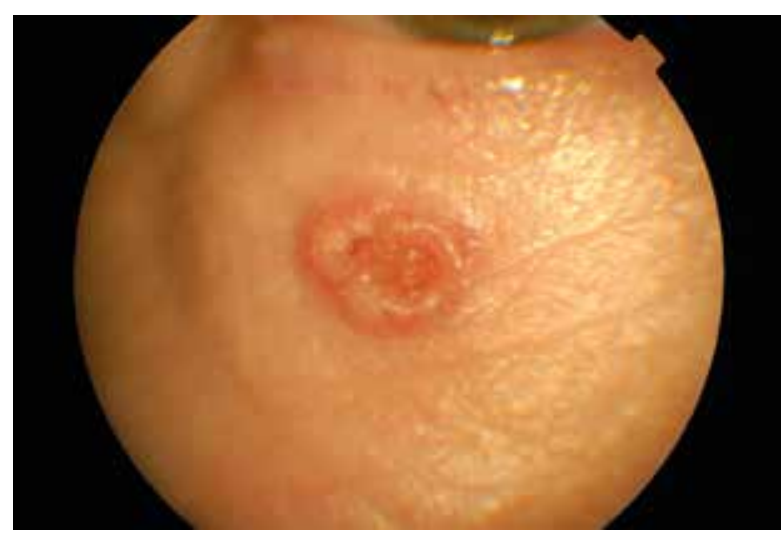

Figure 4. Basal cell carcinoma

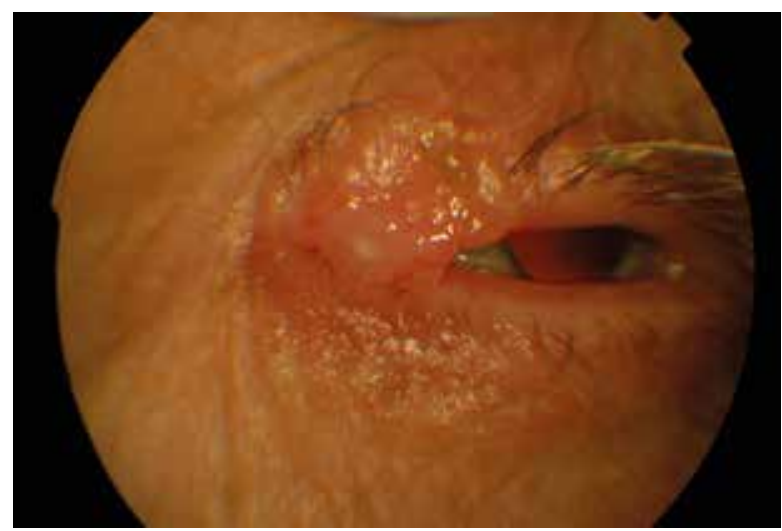

Figure 5. Basal cell carcinoma

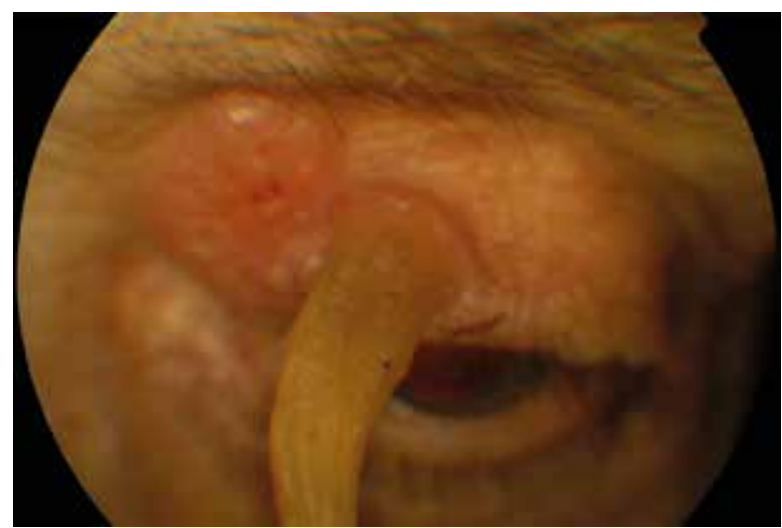

Figure 6. Squamous cell carcinoma (left) with a cutaneous horn (right) arising from its margin
Table 3. Types of basal cell carcinoma in the studied group

\begin{tabular}{lcc}
\hline Type & $\boldsymbol{N}$ & $\%$ \\
\hline Nodular & 46 & 41.8 \\
\hline Ulcerative & 12 & 10.9 \\
\hline Superficial & 10 & 9.1 \\
\hline No type described & 42 & 38.2 \\
\hline
\end{tabular}

Deprez et al. [3] in their extensive study, described the prevalence of 5504 eyelid tumours. The authors reported that benign tumours represented $84 \%$ of all eyelid lesions, which is consistent with our findings in the present study. The most common lesions were squamous cell papilloma (26\%), seborrheic keratosis (21\%), nevus (20\%), hidrocystoma (8\%), and xanthoma/xanthelasma (6\%). The difference in this study is that we included chalazia in the study group and it was the most common benign finding. Huang et al. [4] reported that the most frequent benign subtypes were intradermal nevus (57.8\%) followed by seborrheic keratosis (12.6\%), xanthelasma (11.2\%) and epidermal cyst (8.2\%). Gundogan et al. [5] analysed 1502 cases of eyelid lesions, of which $87.2 \%$ were benign. Among those, the most prevalent were squamous papillomas (37.0\%), followed by seborrheic keratoses (29.3\%) and epidermal cysts (12.2\%). The similarities and differences in the incidence rates of benign tumours can be perhaps attributed to racial and regional distribution factors. Absence of xanthelasma findings in this study is caused by the fact that the diagnosis is made mostly by clinical observation, while this study relied on histopathology results only.

In all previously cited studies, basal cell carcinoma accounted for the most commonly seen malignant eyelid tumour. Deprez et al. [3] reported its incidence in $86 \%$, Gundogan et al. [5] in 95.5\% of malignant eyelid lesions. This high incidence of BCC is also confirmed by other authors $[6,7]$ as well as by our study. There are some reports showing that the prevalence of BCC increases over time [8]. The treatment of choice, especially in the high-risk area of the eyelid is surgical removal using the Moh's technique or a large margin of 2-4 $\mathrm{mm}[9,10]$. Other treatment modalities include radiotherapy or immunotherapy [9].

Squamous cell carcinoma is the second most common malignancy of the eyelid accounting for $5-10 \%$ of all malignant eyelid lesions [3, 11, 12]. Even though SCC is not as common as BCC, it could be much more invasive for the patient as it may metastasise to lymph nodes as well as to the central nervous system due to the perineural invasion [13]. Because of that, the treatment of choice is surgical resection with a more significant margin (4-6 mm) [14].

Other authors suggest that sebaceous gland carcinoma is the second most common eyelid malignancy $[15,16]$ with $34-38 \%$ of prevalence rates. It is unclear why 
this study showed a much lower incidence rate of 1.7\%. Of note, factors such as geographical and racial variations as well as a smaller study group have to be taken into consideration. Sebaceous gland carcinoma may arise from sebaceous glands of the eyelid such as Meibomian glands of the tarsus or Zeiss glands of the hair follicle of the eyelash. It is a particularly dangerous eyelid tumour because it may masquerade as an inflammatory condition and its high metastasis rates reaching up to $41 \%$ [17].

We did not observe in our analysed group cutaneous malignant melanoma arising from the eyelid. However, its occurrence in other studies is also small, accounting for $0.5-3 \%$ of all eyelid tumours $[15,18]$. Most eyelid melanomas are likely to evolve from lentigo maligna precursor lesion that progresses to lentigo maligna melanoma or from a dysplastic nevus. A cutaneous malignant melanoma may invade the lid margin and conjunctiva, in which cases it may be impossible to differentiate if the melanoma originates from the conjunctiva or the skin. Such cases have worse prognosis [19].

\section{Conclusions}

Although benign lesions are the most common eyelid tumours, it is essential to differentiate between benign and malignant eyelid tumours because early detection and appropriate treatment may improve the cosmetic effect and reduce recurrences.

\section{Conflict of interest}

The authors declare no conflict of interest.

\section{References}

1. Bedrossian EH. Embryology and anatomy of the eyelid. In: Duane's Foundation of Clinical Ophthalmology, Ocular Anatomy, Embryology and Teratology. Vol. 1. Tasman W, Jaeger EA (eds). Lippincott Williams \& Wilkins, Philadelphia 2004; 1-24.

2. Cook BE Jr, Bartley GB. Epidemiologic characteristics and clinical course of patients with malignant eyelid tumors in an incidence cohort in Olmsted County, Minnesota. Ophthalmology 1999; 106: 746-50.

3. Deprez M, Uffer S. Clinicopathological features of eyelid skin tumors. A retrospective study of 5504 cases and review of literature. Am J Dermatopathol 2009; 31: 256-62.

4. Huang YY, Liang WY, Tsai CC, et al. Comparison of the clinical characteristics and outcome of benign and malignant eyelid tumors: an analysis of 4521 eyelid tumors in a tertiary medical center. Biomed Res Int 2015; 2015: 453091.

5. Gundogan FC, Yolcu U, Tas A, et al. Eyelid tumors: clinical data from an eye center in Ankara, Turkey. Asian Pac J Cancer Prev 2015; 16: 4265-9.

6. Lee SB, Saw SM, Au Eong KG, et al. Incidence of eyelid cancers in Singapore from 1968 to 1995. Br J Ophthalmol 1999; 83: 595-7.

7. Lim VS, Amrith S. Declining incidence of eyelid cancers in Singapore over 13 years: population-based data from 1996 to 2008. Br J Ophthalmol 2012; 96: 1462-5.
8. Delfino S, Innocenzi D, Di Lorenzo G, et al. An increase in basal cell carcinoma among the young: an epidemiological study in a middle-south Italian population. Anticancer Res 2006; 26: 4979-83.

9. NCCN Guidelines Version 1.2019 Basal Cell Skin Cancer.

10. Auw-Haedrich C, Frick S, Boehringer D, Mittelviefhaus H. Histologic safety margin in basal cell carcinoma of the eyelid. Ophthalmology 2009; 116: 802-6.

11. Inaba K, Ito Y, Suzuki S, et al. Results of radical radiotherapy for squamous cell carcinoma of the eyelid. J Radiat Res 2013; 54: 1131-7.

12. Sun MT, Andrew NH, O'Donnell B, et al. Periocular squamous cell carcinoma: TNM staging and recurrence. Ophthalmology 2015; 122: 1512-6.

13. Loeffler M, Hornblass A. Characteristics and behavior of eyelid carcinoma. Ophthalmic Surg 1990; 21: 513-8.

14. NCCN Guidelines Version 2.2019 Squamous Cell Skin Cancer.

15. Yu SS, Zhao Y, Zhao H, et al. A retrospective study of 2228 cases with eyelid tumors. Int J Ophthalmol 2018; 11: 1835-41.

16. Xu XL, Li B, Sun XL, et al. Eyelid neoplasms in the Beijing Tongren Eye Centre between 1997 and 2006. Ophthalmic Surg Lasers Imaging 2008; 39: 367-72.

17. Wali UK, Al-Mujaini A. Sebaceous gland carcinoma of the eyelid. Oman J Ophthalmol 2010; 3: 117-21.

18. Huang YY, Liang WY, Tsai CC, et al. Comparison of the clinical characteristics and outcome of benign and malignant eyelid tumors: an analysis of 4521 eyelid tumors in a Tertiary Medical Center. Biomed Res Int 2015; 2015: 453091.

19. Pe'er J, Folberg R. Eyelid tumors: Cutaneous melanoma. In: Clinical Ophthalmic Oncology: Eyelid and Conjunctival Tumors. $2^{\text {nd }}$ ed. Pe'er J, Singh AD (eds.). Springer, Berlin 2014; 63-8. 